\title{
The effects of native advertising on consumer responses. Some experimental evidences on the interaction between content type and brand awareness*
}

\author{
Maria Antonietta Raimondo ${ }^{* *}$, Maria Vernuccio ${ }^{* * *}$, \\ Gaetano "Nino" Miceli"
}

\begin{abstract}
Native advertising is rapidly establishing itself in the field of online marketing communication strategies. This paper aims at analyzing consumer responses to native ads varying upon the concreteness versus abstractness of content under specific brand awareness conditions. The conceptual model proposes that brand awareness moderates the relationships between the type of content (concrete $v s$. abstract) and consumers evaluations of and dispositions toward native ad, product/service and brand. The results of an experimental study provide empirical support to the idea that consumer responses to concrete $v s$. abstract native content change for wellknown and less known brands and suggest implications for theory and practice.
\end{abstract}

Keyword: Digital advertising, native advertising, type of content, concreteness, abstractness, brand awareness.

First submission: 01/02/2019, accepted: 28/06/2019

* This paper is the result of the joint effort of the three authors. In the final draft, however, paragraphs 2 and 3 may be attributed to Maria Antonietta Raimondo, the introduction, paragraph 1 and the conclusions may be attributed to Maria Vernuccio, and paragraph 4 may be attributed to Gaetano "Nino" Miceli.

** Associate Professor of Marketing, Department of Business Administration and Law, Cubo 3C - University of Calabria, Campus of Arcavacata, Via P. Bucci, 87036 Rende (CS) - Italy; Tel: +39 0984 492248; e-mail: ma.raimondo@unical.it.

*** Associate Professor of Management, Department of Management, Sapienza Università di Roma, Via del Castro Laurenziano 9 -00161 Roma - Italy; e-mail: maria.vernuccio@ uniroma1.it.

**** Assistant Professor of Marketing, Department of Business Administration and Law, Cubo 3C - University of Calabria, Campus of Arcavacata, Via P. Bucci, 87036 Rende (CS) - Italy; Tel: +39 0984 492162; e-mail: g.miceli@unical.it.

Mercati \& Competitività (ISSN 1826-7386, eISSN 1972-4861), 2019, 3 


\section{Introduction}

In the rapidly evolving world of digital advertising, scholars and practitioners agree in recognizing the growing relevance of native advertising as a form of advertising that is strongly integrated with the online editorial content, thus improving levels of exposure, acceptance and engagement for paid branded content (Kim, 2017). In fact, native advertising can be an answer to some significant issues for different players in the digital advertising industry.

For advertisers, native advertising is a useful tool to tackle challenges such as the well-known phenomenon of "banner blindness" (e.g., Cho and Cheon, 2004; Drèze and Hussherr, 2003; Pasqualotti and Baccino, 2014; Sajjacholapunt and Ball, 2014), the increasing costs of gaining user attention (Brown, 2011), and the low level of user interest in classic display formats. As a matter of fact, whereas the average click-through rate (CTR) for banners is about $0.09-0.11 \%$, the average CTR for native advertising is $0.8 \%$ (Appnexus, 2018). For publishers, native advertising can be a valid means to fight critical phenomena such as the increasing user rejection of the most intrusive ad formats, as evidenced by the growing popularity of "adblocking" systems (IAB, 2016). Consequently, the native advertising market has shown substantial growth worldwide, reaching \$16 billion (US) in revenue in 2017 alone (Appnexus, 2018).

The academic literature features articles on definitions and forms of native advertising (Wojdynski, 2016), user perceptions of native advertising compared to display advertising, as well as of different characteristics of native ads (Aribarg and Schwartz, 2017), and native communication strategies adopted by firms using different formats, messages, media and devices to achieve both branding and conversion goals (Harms, Bijmolt and Hoekstra, 2017).

This paper contributes to the research stream that analyzes the effects of native advertising from the consumer perspective. Previous studies have mainly focused on the disclosure characteristics of native ads (e.g., wording and positioning of the label, visual prominence, brand presence) that can influence the recognition of native content as advertising and, therefore, attitudes toward the message and the brand (Wojdynski and Evans, 2016; Krouwer, Poels and Paulussen, 2017). However, few research exists on the effects of different types of native content on consumer responses. Our aim is to analyze consumer responses to certain features characterizing the content of native advertising under specific conditions of brand awareness. By distinguishing between native content that provides concrete $v s$. abstract information about the firm's offering, the proposed conceptual model suggests that brand awareness moderates the relationships between the type of content 
and consumers evaluations of and dispositions toward native ad, product/service and brand. The results of an experimental study provide empirical support to the idea that consumer responses to concrete $v s$. abstract native content are different for well-known and less known brands.

The paper is organized as follows. First, we present a brief review of the native advertising literature that provides the theoretical background of our research. Then, we develop our conceptual model and research hypotheses. Subsequently, we report the research design and the results of the experimental study. Finally, we discuss the theoretical and managerial implications of our research.

\section{Theoretical background}

Native advertising represents a complex set of highly heterogeneous and constantly evolving digital advertising formats. Hence, scholars and practitioners have encountered many obstacles in formulating a widely accepted definition. Even today, one of the key themes in the field of native advertising studies concerns the issue of defining native advertising and its specific formats. To this end, an important contribution was made in 2019 by the IAB (Interactive Advertising Bureau), which defined native advertising as «paid ads that are so cohesive with the page content, assimilated into the design, and consistent with the platform behavior that the viewer simply feels that they belong» (p. 11). Therefore, native advertising is strongly integrated into editorial content (Wojdynski, 2016) with reference to aspects such as page design, positioning, and function, that is, type of content experience. In this way, the different formats of native advertising do not interrupt the user browsing experience and, even if explicitly identified as sponsored elements (e.g., "sponsored by", "sponsored content", "advertisement"), offer a brand experience that is relatively contextualized and coherent in terms of both form and content (Vaccaro, 2016). Minimal intrusiveness and greater attractiveness compared to traditional ad formats make it possible to reach a broad range of branding objectives (e.g., awareness, engagement) and of direct response (e.g., downloading an app) using a wide variety of formats. According to the most common international usages, these formats can be sorted into three macro-categories (IAB, 2019):

- In-feed unit, in which the ad is "camouflaged" as editorial or social content, as we will explain later; 
- Content recommendation widget, which inserts the ad as "recommended content" in an ad hoc section of an editorial page (not on the home page) and is linked to an external page;

- Branded/Native content, which is based on a paid content from a brand that is inserted "in the same format as full editorial on a publisher's site" (IAB, 2019, p. 7).

The category called in-feed unit is the most relevant from the economic point of view (IAB, 2019), as well as the richest in variants, and consequently one of the most studied format in the academic literature (e.g., Aribarg and Schwartz, 2017; Krouwer et al., 2017; Wojdynski et al., 2017). In this case, the native ad is formed of multimedia elements (e.g., images, video) and descriptive text (e.g., title, description) that are consistently inserted in the editorial context so as to be easily confused with such content in the absence of disclosure (e.g., "sponsored by"). For instance, in-feed units can be contextualized in the content stream of social platforms (e.g., Facebook, Instagram), on the home page of a news website (e.g., Forbes, Yahoo!), or on websites and mobile applications that show lists of products (e.g., Amazon, Etsy). In the most common forms, the native ad is linked to a web page that can be either internal ("endemic-feed") or external ("linked in-feed ad") to the host site. Such page provides more extensive content and is an integral part of the in-feed unit. Therefore, the in-feed category includes the so-called "sponsored article" that allows to develop more extensive text and multimedia content aimed to build positive brand associations.

In addition to the issue of defining native advertising and its different formats, studies in the field of native advertising have also focused on analyzing consumer responses to native ads compared to traditional display ads and to different features of native ads themselves. Related to the former issue, scholars have found that native ads are less likely to be recognized as advertising compared to traditional banners (Howe and Teufel, 2014), but native ads can capture greater attention, resulting in higher brand recognition and clickthrough rate (Aribag and Schwartz, 2017). Moreover, through repeated exposure to news websites, consumers learn to avoid display ads to a larger extent than native ads. Related to the latter issue, scholars have mostly examined the effects of different styles of native ads disclosure. Generally, higher levels of disclosure (e.g., more prominent brand logo and name, high brand presence, more evident positioning, wording labels using "advertising" or "sponsored") increase ad and brand recognition (e.g., Wojdynki and Evans, 2016; Aribarg and Schwartz, 2017) or attitudinal persuasion knowledge (Krouwer et al., 2017), the latter being the consumer assessment as to whether the advertiser persuasion attempt is inappropriate, unfair, or manipulative. Higher brand 
recognition or attitudinal persuasion knowledge, in turn, have been shown to negatively influence ad and brand evaluations. Higher brand recognition may also comes at the cost of clicks (Aribarg and Schwartz, 2017). Therefore, a trade-off exists between brand recognition and brand evaluation, thus suggesting that there may be characteristics of the native content or of the advertiser that, holding constant disclosure features, interact in determining evaluative and dispositional responses to native advertising.

\section{Conceptual model}

This research focuses on the in-feed unit category of native advertising, considering the format of sponsored articles, with the aim of analyzing the interaction between the type of ad content presented in the article and brand awareness on consumer responses. For the purposes of our study, we classify native content as either concrete or abstract. In order to define the level of concreteness versus abstractness of descriptive content, some scholars used the Linguistic Category Model (Schellekens, Verlegh and Smidts, 2010), which is based on different types of verbs versus adjectives used in the text. However, in our study, we refer to the psychology and marketing literature that, consistently with a means-end perspective (e.g., Gutman, 1982; Olson and Reynolds, 1983), considers content as concrete if it describes material aspects accessible to the senses, that is tangible and measurable attributes of the product/service that are directly perceivable by the consumer. Conversely, abstract content is more conceptual in nature and not directly perceivable with the senses (DubeRioux, Regan and Schmitt, 1990; Lachner and Nückles, 2015). Abstract content refers to the benefits associated with the product/service and to the consumer values, which emerge through causal connections and mental patterns (Solomon, Bamossy, Askegaard and Hogg, 2016).

Previous studies have analyzed the impact of different levels of concreteness versus abstractness of information or advertising messages on consumer responses (Davis, 1994; Capestro, Amatulli and Pichierri, 2018) producing mixed results. According to some scholars, concrete information is more vivid, creating clearer, more distinct images in consumers' minds (Marks, 1973). Therefore, concrete information is more effective in its ability to attract attention and to increase memorization, judgments and persuasion (Holmes and Langford, 1976; Moeser, 1974). Other studies, however, have shown opposite effects. Hinds, Patterson and Pfeffer (2001) highlighted how, in the field of advanced training, abstract information communicated by experts helps to transfer learning between different tasks. Moreover, Burgoon, 
Henderson and Markman (2014) emphasized how abstraction «shifts people's system of thinking and consequently plays a key role in learning, judgment and decision making, and behavion> (p. 515).

In the marketing literature, several authors have found abstract content to have a greater effect on consumer responses under certain conditions. Yang, $\mathrm{Li}$, Tao and $\mathrm{Li}$ (2018) presented empirical evidence on the greater effectiveness of abstract content in search engine advertising when consumers are searching for generic keywords. De Angelis et al. (2017) showed how users' recommendations are more effective in terms of attitude and purchase intention toward a service when the language is abstract, particularly if the consumer has already some knowledge about the service. With reference to advertising messages, Capestro et al. (2018) highlighted the greater influence of abstract content in terms of consumer attitudes toward the ad when the consumer has previous knowledge about the product.

These studies suggest that brand awareness can be linked to the role played by concreteness versus abstractness of the content in native advertising. Brand awareness brings a concept of consciousness into the minds of consumers that varies based on their degree of brand knowledge (Aaker, 1991).

Literature on the role of previous knowledge in the consumer learning (Gregan-Paxton and John, 1997; Gregan-Paxton et al., 2002) argues that individuals with different levels of knowledge process marketing stimuli differently, thus suggesting that consumer responses to different types of native content may change depending on the degree of brand awareness. When the level of brand knowledge is very high, information processing is based on higher-order conceptual categories that generate preferences, desires, emotions, sensations, modifying or extending existing knowledge structures. Therefore, for wellknown brands, we expect that native articles featuring abstract information will receive more favorable responses than native articles featuring concrete information. On the contrary, when the level of brand knowledge is still limited, information processing is based on lower-order conceptual categories that allow a greater awareness of what the product/service offers, thus creating new knowledge structures. Therefore, for less known brands, we expect that native articles featuring concrete information will receive more favorable responses than native articles featuring abstract information.

In the proposed conceptual model, consumer responses taken into consideration concern evaluations and dispositions toward 1) the sponsored article (attitude and intention to share it on social network), 2) the product/service (intention to buy and willingness to pay) and 3) the brand (attitude and Consumer Brand Engagement - CBE). Formally, we formulate the following research hypotheses: 
$\mathbf{H}_{1}$ : The type of native content and brand awareness interact in determining consumer responses toward the sponsored article. Specifically: a) for well-known brands, abstract native content will receive more favorable responses than concrete native content; $b$ ) for less known brands, the opposite pattern will hold.

$\mathbf{H}_{2}$ : The type of native content and brand awareness interact in determining consumer responses toward the product/service. Specifically: $a$ ) for wellknown brands, abstract native content will receive more favorable responses than concrete native content; $b$ ) for less known brands, the opposite pattern will hold.

$\mathbf{H}_{3}$ : The type of native content and brand awareness interact in determining consumer responses toward the brand. Specifically: a) for well-known brands, abstract native content will receive more favorable responses than concrete native content; $b$ ) for less known brands, the opposite pattern will hold.

Figure 1 shows the proposed conceptual model.

Figure 1 - Conceptual model

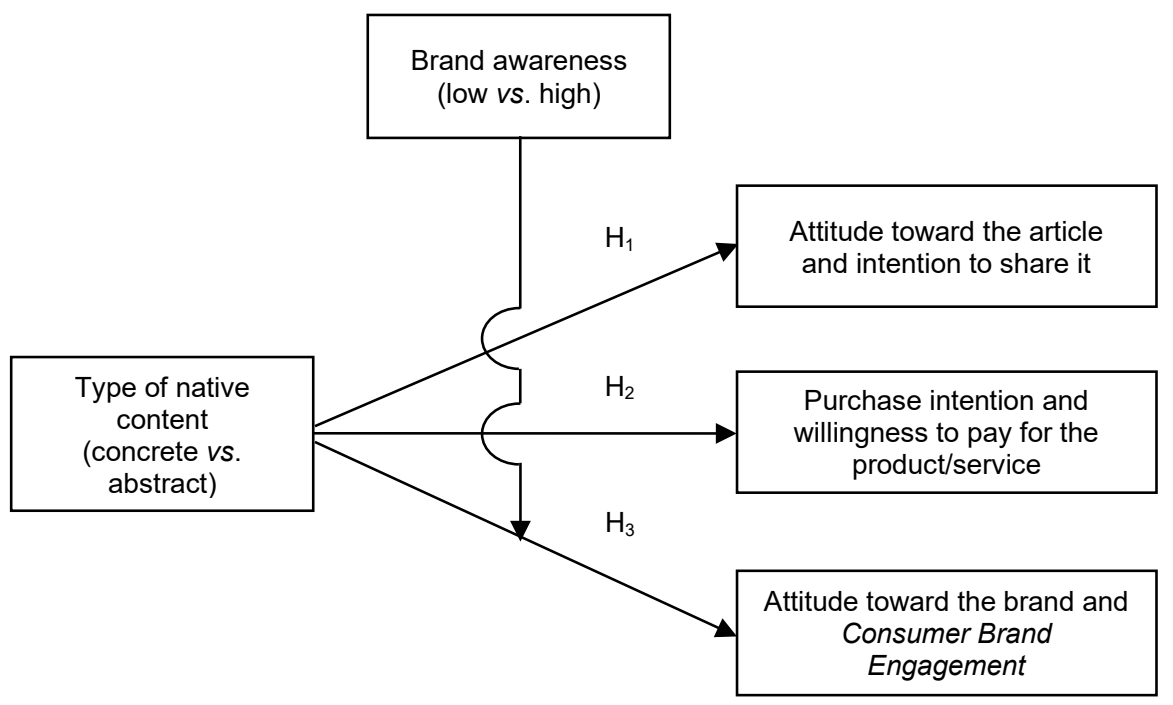




\section{Research design}

In order to test the proposed conceptual model, we conducted an experimental study on a sample of undergraduate students at a large Italian University. Participants were exposed to and then asked to evaluate a sponsored in-feed article about cruise vacations. The article was ostensibly published by the online edition of La Repubblica, which is one of the leading online Italian newspapers in routinely adopting innovative forms of digital and native advertising.

Experimental design. The study was a 2 (Type of native content: concrete $v s$. abstract) $\times 2$ (Brand awareness: low vs. high) between-subjects design. We manipulated type of content by describing, in both the title and the article, the services offered by cruising boats with an emphasis on either tangible attributes and physical characteristics (e.g., functional rooms, well-equipped swimming pools, and good restaurants) in the concrete content conditions or benefits and values (e.g., relax, enjoyment, and tastes) in the abstract content conditions. We manipulated brand awareness using MSC, in the high brand awareness conditions, and Regent, in the low brand awareness conditions.

For each of the four experimental conditions, we created two visual stimuli (in Italian): The native ad, embedded in Repubblica.it home page, and the corresponding sponsored article linked to the native ad. A research assistant created the native ad by digitally manipulating the website home page ${ }^{1}$. Digital modifications were applied by means of a Java code. Specifically, the ad was composed including:

a) the title of the section (Travel);

b) a picture related to cruise travels;

c) the title and subtitle of the ad, manipulated in terms of concrete $v s$. abstract format;

d) the "Sponsored content" label, in the top-right corner, and the "By [MSC vs. Regent] label, in the bottom-left corner.

The research assistant created the sponsored article by digitally modifying a real article from the Native section of the Repubblica.it website. Specifically, the article was composed including:

a) the title of the Native section (Travel);

b) the same picture used in the corresponding native ad, in a larger format and in the top-right area of the web page;

c) the same title and subtitle presented in the corresponding native ad;

d) the "Native" label, in the top-center section, and the "Sponsored content" label, in the top-right section;

\footnotetext{
${ }^{1}$ The authors wish to thank the research assistant Rocco Pati for the support in designing and collecting data in the experimental study.
} 
e) the article itself, based on an introductory section on sea-travels (the same for all experimental conditions), a general description of cruise services in concrete $v s$. abstract format, a specific description of the cruise services offered by MSC $v s$. Regent, again in a concrete $v s$. abstract format, a picture of a MSC vs. Regent cruise boat, a further description of cruise services offered by MSC $v s$. Regent in concrete $v s$. abstract format, and a final sentence on sea-travels (the same for all experimental conditions). The full text of the article used in the experimental conditions is reported in the Appendix. All the descriptions basically features the same number of words (i.e., 207 words in the concrete article vs. 205 words in the abstract article).

All experimental stimuli featured the same type-font, design, colors and style, which were all consistent with the selected digital platform. These applications allowed us to keep the stimuli constant but for the manipulated elements related to the independent variables of our conceptual model. Figure 2 shows the stimuli for the four experimental conditions.

Procedure and sample. Participants $\left(N=160,58.1 \%\right.$ female, $M_{\text {age }}=$ $22.79, S D_{\text {age }}=2.34$ ) were management undergraduate students at a large Italian University who participated voluntarily in an online study. Students received emails including a link to the study (created with Qualtrics) and were randomly assigned to one of the four experimental conditions. Participants were first exposed to the native ad. Assuming they wanted to get more information about cruise vacations, they were subsequently guided toward a sponsored article on cruise services, by clicking on an arrow, and asked to read it attentively. This procedure simulated effectively the working sequence native ad-sponsored article, which is common in native advertising platforms. After reading the article, participants answered a set of questions aiming to measure the dependent variables, concerning, in more detail:

- Attitude toward the article, measured by two 7-point semantic differential items: "Please express your evaluation on the article you have just read", 1 = awful vs. 7 = great; 1 = unfavourable $v s .7=$ favourable (adapted from Krouwer et al., 2017); internal consistency for the scale was satisfactory $(\alpha=0,71)$, therefore we averaged the two items to form an attitude toward the article index;

- Intention to share the article, measured by one 7-point item: "To what extent you will be willing to share this article on social media (Facebook, Twitter, Instagram, etc.)?", 1 = not at all, 7 = very much (Sohn, 2009);

- Intention to purchase the cruising travel, measured by one 7-point Likert item: "I would like to buy the cruise described in the article", 1 $=$ definitely disagree, $7=$ definitely agree (Krouwer et al., 2017); 
Maria Antonietta Raimondo, Maria Vernuccio, Gaetano “Nino” Miceli

- willingness to pay for the cruising travel, measured by an open-ended question: "How much would you pay for the cruise described in the article? Please type a number between 0 and 800 euro";

Figure 2 - Experimental conditions and stimuli

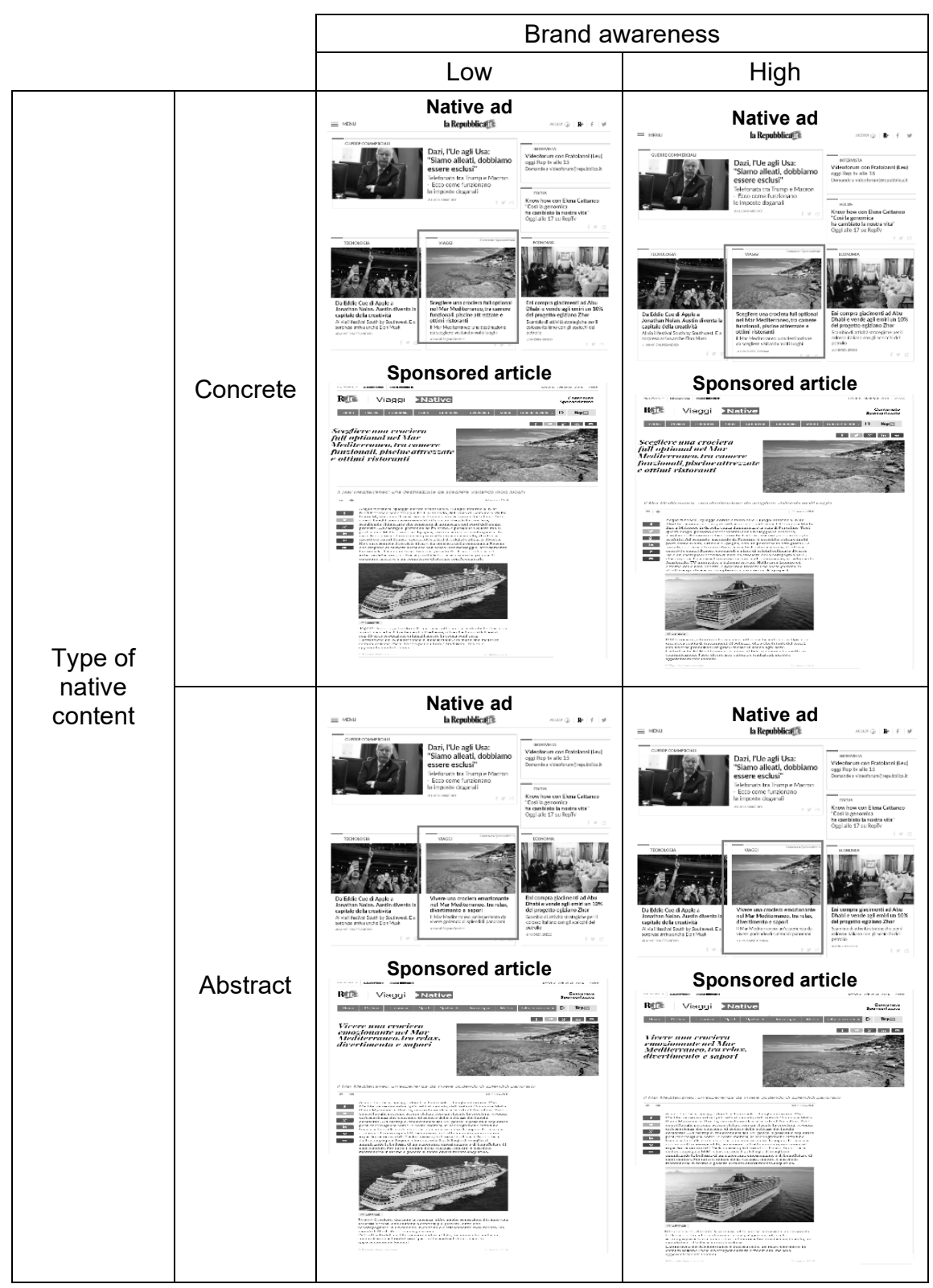

158 
- Attitude toward the brand, measured by three 7-point semantic differential items: "Please express your evaluation of MSC/Regent", 1 = unfavourable $v s .7=$ favourable; $1=$ negative $v s .7=$ positive; $1=$ low quality $v s .7=$ high quality (Boerman, van Reijmersdal and Neijens, 2012); internal consistency for the scale was satisfactory $(\alpha=0.88)$, therefore we averaged the three items to create an attitude toward the brand index;

- Consumer Brand Engagement (CBE), measured by two 7-point Likert items on cognitive CBE - "I put attention on everything that regards MSC/Regent"; "I focus my attention on MSC/Regent", 1 = definitely disagree, 7 = definitely agree; two 7-point Likert items on affective CBE - "I am enthusiastic about MSC/Regent"; "I love MSC/Regent", $1=$ definitely disagree, $7=$ definitely agree; and two 7-point Likert items on behavioural CBE - "I share with others my ideas on MSC/Regent"; "I share with others positive things on MSC/Regent", $1=$ definitely disagree, 7 = definitely agree; adapted from So, King, Sparks and Wang (2016) and from Dessart, Veloutsou and Morgan-Thomas (2016). An exploratory factor analysis showed that the six items loaded on a single factor (explained variance $57 \%, \alpha=0.88$ ), therefore we averaged the six items to form a CBE index.

Finally, participants answered two manipulation check measures - a 7point semantic differential item on type of content ("Information in the article seemed oriented to emphasize", 1 = decidedly attributes of a cruise travel, 7 = decidedly benefits obtained from a cruise travel) and a 7-point semantic differential item on brand awareness ("To what extent you know MSC/Regent?", $1=$ not at all, $7=$ very much), and indicated their gender and age.

\section{Results}

Results of t-tests on the type of content $\left(M_{\text {Concrete }}=4.64, M_{\text {Abstract }}=5.13\right.$, $t(158)=1.94, p=0.05)$ and on brand awareness $\left(M_{M S C}=3.99, M_{\text {Regent }}=2.04\right.$, $t(158)=8.80, p=0.000)$ items suggested that manipulations of the two independent variable were successful.

We then conducted a series of ANOVA to test the prediction that type of native content and brand awareness interact in determining consumers responses toward the article $\left(\mathrm{H}_{1}\right)$, the product/service $\left(\mathrm{H}_{2}\right)$ and the brand $\left(\mathrm{H}_{3}\right)$. Results of a first ANOVA on attitude toward the article showed non-significant direct effects of type of content $\left(M_{\text {Concrete }}=5.09, M_{\text {Abstract }}=5,12\right.$; $F(1,156)=0.01, p=0.94)$ and of brand awareness $\left(M_{M S C}=5.13, M_{\text {Regent }}=\right.$ 
$5.07 ; F(1,156)=0.10, p=0.75)$. We instead found a significant type of content $\times$ brand awareness interaction $(F(1.156)=5.96, p=0.02)$. Planned comparisons showed that, with high brand awareness (i.e., $M S C$ ), an article featuring abstract content obtained more favourable evaluations than an article featuring concrete content $\left(M_{\text {Concrete_MSC }}=4.88, M_{\text {Abstract_MSC }}=5.35 ; F(1.156)\right.$ $=3.21, p=0.07$ ), whereas, with low brand awareness (i.e., Regent), the opposite pattern holds $\left(M_{\text {Concrete_Regent }}=5.28, M_{\text {Abstract_Regent }}=4.83 ; F(1.156)=\right.$ $2.76, p=0.10$ ), although both contrasts are marginally significant.

Results of an ANOVA on intention to share the article showed a nonsignificant direct effect of type of content $\left(M_{\text {Concrete }}=3.08, M_{\text {Abstract }}=3.36\right.$; $F(1.156)=1.42, p=0.23)$, a significant direct effect of brand awareness $\left(M_{M S C}=2.95, M_{\text {Regent }}=3.49 ; F(1.156)=4.30, p=0.04\right)$, and a marginally significant type of content $\times$ brand awareness interaction $(F(1.156)=3.61, p$ $=0.06$ ). Planned comparisons showed that, with high brand awareness, an article featuring abstract content produces higher intention to share than an article featuring concrete content $\left(M_{\text {Concrete_MSC }}=2.49, M_{\text {Abstract_MSC }}=3.34\right.$; $F(1.156)=4.87, p=.03)$, whereas, with low brand awareness, no significant differences did emerge $\left(M_{\text {Concrete_Regent }}=3.58, M_{\text {Abstract_Regent }}=3.39 ; F(1.156)\right.$ $=0.24, p=0.62)$. Figure 3 shows the results for the two dependent variables concerning the sponsored article which, overall, partially support $\mathrm{H}_{1}$.

Figure 3 - Attitude toward the article and intention to share the article as functions of type of content and brand awareness
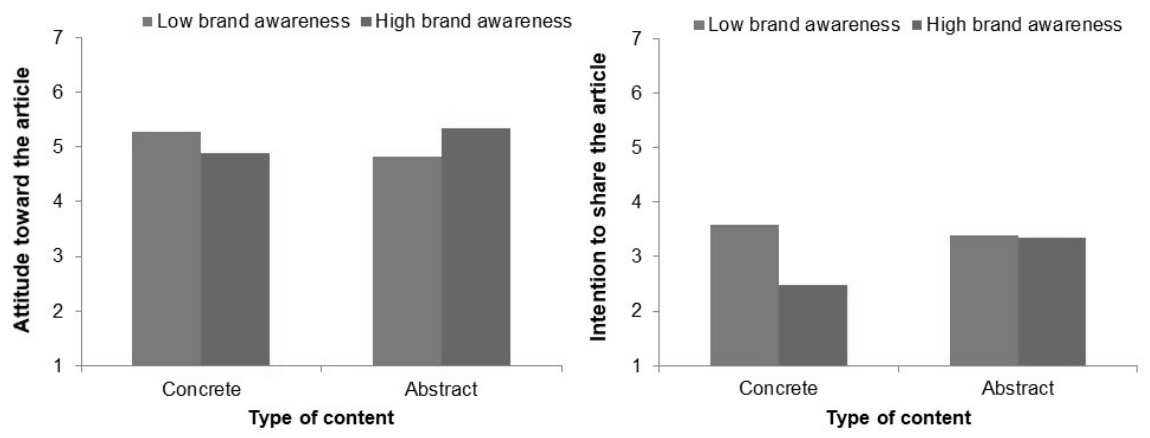

Results of an ANOVA on purchase intention showed non-significant direct effects of type of content $\left(M_{\text {Concrete }}=4.69, M_{A b s t r a c t}=5.04 ; F(1.156)=\right.$ $2.41, p=0.12)$ and of brand awareness $\left(M_{M S C}=4.77, M_{\text {Regent }}=4.96 ; F(1.156)\right.$ $=0.95, p=0.33)$. We found, however, a significant type of content $\times$ brand awareness interaction $(F(1.156)=6.57, p=0.01)$. Planned comparisons showed that, with high brand awareness, an article featuring abstract content 
produces higher purchase intention than an article featuring concrete content $\left(M_{\text {Concrete_MSC }}=4.24, M_{\text {Abstract_MSC }}=5.20 ; F(1.156)=8.58, p=0.004\right)$, whereas, with low brand awareness, no significant differences did emerge $\left(M_{\text {Concrete_Regent }}=5.07, M_{\text {Abstract_Regent }}=4.83 ; F(1.156)=0.51, p=0.48\right)$.

Results of an ANOVA on the natural logarithm of willingness to pay showed non-significant direct effects of type of content $\left(M_{\text {Concrete }}=6.00\right.$, $\left.M_{\text {Abstract }}=6.12 ; F(1.156)=1.07, p=0.30\right)$ and of brand awareness $\left(M_{M S C}=\right.$ $\left.6.03, M_{\text {Regent }}=6.10 ; F(1.156)=0.50, p=0.48\right)$. A significant type of content $\times$ brand awareness interaction $(F(1.156)=4.14, p=0.04)$ did instead emerge. Planned comparisons showed that, with high brand awareness, an article featuring abstract content generates higher willingness to pay than an article featuring concrete content $\left(M_{\text {Concrete_MSC }}=5.83, M_{\text {Abstract_MSC }}=6.19 ; F(1.156)\right.$ $=4.77, p=0.03$ ), whereas, with low brand awareness, we observed similar willingness to pay across the two type of content conditions $\left(M_{\text {Concrete_Regent }}=\right.$ $\left.6.15, M_{\text {Abstract_Regent }}=6.04 ; F(1.156)=0.50, p=0.48\right)$. Figure 4 shows the results for the two dependent variables describing dispositions toward the product/service which, overall, partially support $\mathrm{H}_{2}$.

Figure 4-Purchase intention and willingness to pay as functions of type of content and brand awareness
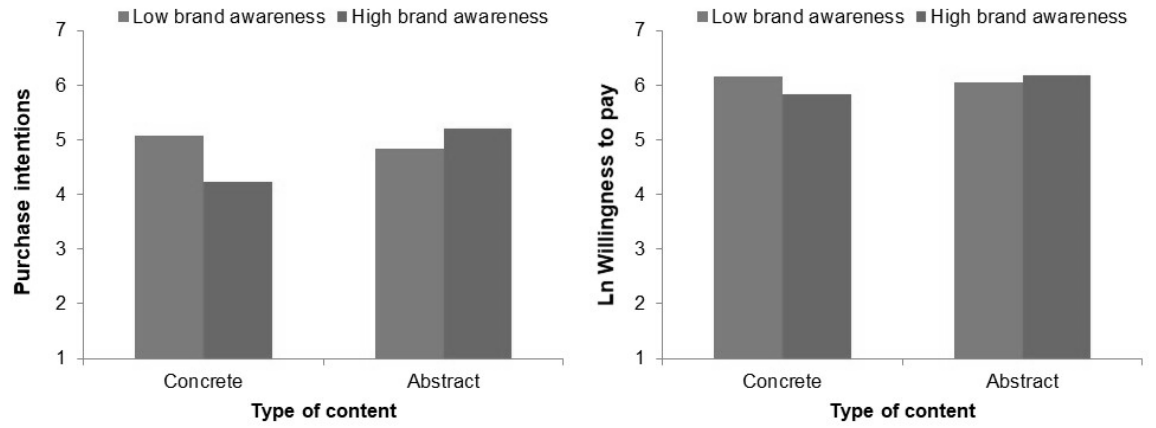

Results of an ANOVA on attitude toward the brand showed a non-significant direct effect of type of content $\left(M_{\text {Concrete }}=5.16, M_{\text {Abstract }}=5.36\right.$; $F(1.156)=0.60, p=0.44)$, a marginally significant direct effect of brand awareness $\left(M_{M S C}=5.45, M_{\text {Regent }}=5.07 ; F(1.156)=3.21, p=0.07\right)$, and a significant type of content $\times$ brand awareness interaction $(F(1.156)=3.84, p=$ 0.05 ). Planned comparisons showed that, with high brand awareness, an article featuring abstract content determines more favourable attitude toward the brand than an article featuring concrete content $\left(M_{\text {Concrete } M S C}=5.14\right.$, $\left.M_{\text {Abstract_MSC }}=5.70 ; F(1.156)=3.78, p=0.05\right)$, whereas, with low brand 
awareness, no significant differences were observed $\left(M_{\text {Concrete_Regent }}=5.17\right.$, $\left.M_{\text {Abstract_Regent }}=4.93 ; F(1.156)=0.69, p=0.41\right)$.

Finally, results of an ANOVA on $C B E$ showed non-significant direct effects of type of content $\left(M_{\text {Concrete }}=3.04, M_{\text {Abstract }}=3.40 ; F(1.156)=2.38, p=\right.$ $0.12)$ and of brand awareness $\left(M_{M S C}=3.41, M_{\text {Regent }}=3.03 ; F(1.156)=2.73, p\right.$ $=0.11)$. We found a significant type of content $\times$ brand awareness interaction $(F(1.156)=4.34, p=0.04)$. Planned comparisons showed that, with high brand awareness, an article featuring abstract content generates higher CBE than an article featuring concrete content $\left(M_{\text {Concrete_MSC }}=2.99, M_{\text {Abstract_MSC }}=\right.$ $3.75 ; F(1.156)=6.65, p=.01$, whereas, with low brand awareness, we observed similar CBE scores across the two type of content conditions $\left(M_{C o n-}\right.$ crete_Regent $\left.=3.08, M_{\text {Abstract_Regent }}=2.97 ; F(1.156)=0.14, p=0.71\right)$. Figure 5 depicts the results for the two dependent variables describing evaluations of the brand which, overall, partially support $\mathrm{H}_{3}$.

Figure 5 - Attitude toward the brand and CBE as functions of type of content and brand awareness
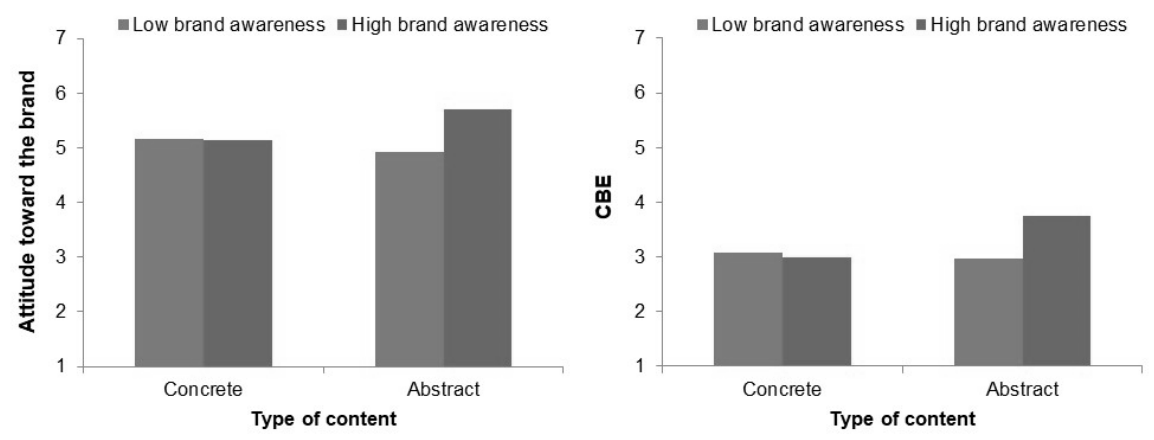

Findings generally support our predictions on the interaction between type of native content and brand awareness on consumer responses, with specific reference to the effect of type of content for well-known brands. Across different dependent variables, we consistently found that abstract content determines better consumer reactions compared to concrete content. Differently, the reported empirical evidence does not provide enough support for what concerns our expectations for less known brands. For these brands, articles featuring concrete content generally obtained better consumer reactions than articles featuring abstract content, but these differences did not approach conventional significance thresholds. A possible explanation of this evidence may concern the specific setting of the study, that is, cruise 
vacations. The nature of service offered by cruise companies could have activated information processing approaches more consistent with abstract than concrete conceptual categories. An additional explanation could be the lack of statistical power that larger samples might solve.

\section{Conclusions}

This paper proposes a conceptual model in order to explain the interaction between type of native advertising content and brand awareness. The results show that, as far as well-known brands are concerned, consumer evaluations and dispositions improve when sponsored articles contain abstract rather than concrete information.

From a theoretical point of view, the paper contributes to the marketing literature in several ways. First, it is the first empirical work that tries to fill a research gap in studies on native advertising, which have so far under-investigated the role played by a key message factor such as the characteristic of the content, focusing instead on disclosure features of native ads (e.g., Wojdynki and Evans, 2016; Aribarg and Schwartz, 2017). With specific reference to the in-feed/sponsored article format, our results have highlighted how the level of concreteness versus abstractness of native content can influence consumer responses depending on the different levels of brand awareness.

Second, this study contributes to the research stream that investigates the role of prior knowledge in consumer responses to marketing stimuli (Bansal and Voyer, 2000; De Angelis et al., 2017), specifically considering brand awareness as a relevant moderating variable. Furthermore, our results extend knowledge of consumer learning theory (Gregan-Paxton and John, 1997; Gregan-Paxton et al., 2002), by empirically demonstrating how the process of abstraction - determined by the type of content and significantly favored by high level of brand awareness - positively influences consumer responses under multiple aspects (evaluative, relational and behavioral), toward the advertising, the product/service and the brand.

From a managerial point of view, the results suggest that, for branded companies with high levels of awareness, online marketing communication through a sponsored article format should use abstract content in the title and in the text, featuring benefits and values of the offer, rather than tangible and measurable aspects. This would allow the optimization of the investments in native advertising, achieving more favorable consumer responses. First, through abstract native content, well-known brands could achieve better advertising results in terms of both attitude toward the article and intention to 
share it. Second, by resorting to abstract information, well-known brands could increase the intention to buy and the willingness to pay. Third, brand performances could be improved through content marketing strategies centered on abstractness of native messages. In particular, it would be possible to improve brand results not only in terms of evaluation (i.e., attitude toward the brand) but also from a relational standpoint, that is, in terms of consumer brand engagement, one of the prior strategic objectives of nowadays digital advertising.

This paper is not exempt from limitations, which can be overcome by future research. First, our study focused on a particular service, that is, cruise vacations. Future research could focus on other types of services, as well as on tangible products. Second, since the procedure used in the experiment forced participants to click on the native ad and to read the sponsored article, we did not control for participants' levels of interest toward cruise tourism. However, randomization of participants in the four experimental conditions made it possible to control for external factors due to variations in participants' characteristics. Third, the proposed conceptual model did not consider individual differences. Future research could identify specific characteristics that may have an impact on the interplay between type of native content and brand awareness, such as analytic $v s$. holistic thinking style, skepticism toward advertising or motivation to internet usage (goal-directed vs. experiential). Fourth, this paper provides preliminary evidences on the interaction between the level of concreteness versus abstractness of native content and the level of brand awareness that future research would aim to generalize using different samples of respondents. We conducted an experiment on a sample of undergraduate students who may not represent the main target of cruise companies. Future research should employ a sample of real customers to extend the validity of the analysis. In spite of these limitations, this research aims to provide knowledge and to stimulate further investigation on a form of advertising, native advertising, the relevance of which is rapidly growing in online marketing communication strategies. 


\section{Appendix - Text of the sponsored articles used in the experi- mental stimuli}

\section{Low/High Brand Awareness - Concrete native content conditions}

\section{Title}

Scegliere una crociera full optional nel Mar Mediterraneo, tra camere funzionali, piscine attrezzate e ottimi ristoranti.

Subtitle

Il Mar Mediterraneo: una destinazione da scegliere visitando molti luoghi.

Text of the article

Introductory section on sea-travels common to all experimental conditions

Acque turchesi, spiagge dorate e tanto sole. I luoghi intorno al Mar Mediterraneo sono tra i più belli al mondo, dall'isola di Comino a Malta fino a Mykonos in Grecia, senza dimenticare la baia di Portofino.

General description of cruise services in concrete format

Tutti questi luoghi possono essere visitati con un viaggio in crociera, scegliendo l'itinerario che consente di attraccare nei porti dei luoghi preferiti. Ad esempio, partendo da Palermo, è possibile visitare molti posti come Malta, Francia e Spagna, con un percorso in otto giorni. Le navi da crociera offrono un'ampia scelta di cabine e suite, strutture sportive e centri fitness, spettacoli e piatti di origini culinarie diverse.

Specific description of the cruise services offered by Regent vs. MSC in concrete format $\mathrm{Ne}$ è un esempio il servizio di navi da crociera della compagnia Regent/MSC, che dispone di camere lussuose con vasca idromassaggio, arredamento funzionale, TV interattiva e balcone privato. Nelle aree interne ed esterne delle navi, inoltre, è possibile trovare una vasta gamma di strutture sportive e un complesso di piscine con Acquapark.

[Picture of a Regent vs. MSC cruise boat]

Specific description of cruise services offered by Regent vs. MSC in concrete format Regent/MSC crociere, a bordo delle sue navi, offre anche autentiche Spa, con una ricca scelta di trattamenti di bellezza, oltre che futuristici teatri, con diverse produzioni originali messe in scena ogni sera.

Final sentence on sea-travels common to all experimental conditions

L'attrattività del Mediterraneo è indiscutibile, un mare che mette in comunicazione Paesi diversi per cultura e tradizioni, ma solo apparentemente lontani.

\section{Low/High Brand Awareness - Abstract native content conditions Title}

Vivere una crociera emozionante nel Mar Mediterraneo, tra relax, divertimento e sapori. Subtitle

Il Mar Mediterraneo: un'esperienza da vivere godendo di splendidi panorami.

\section{Text of the article}

Introductory section on sea-travels common to all experimental conditions

Acque turchesi, spiagge dorate e tanto sole. I luoghi intorno al Mar Mediterraneo sono tra i più belli al mondo, dall'isola di Comino a Malta fino a Mykonos in Grecia, senza dimenticare la baia di Portofino. 
General description of cruise services in abstract format

Tutti questi luoghi possono essere visitati con un viaggio in crociera, vivendo un'esperienza che consente di godere delle bellezze dei luoghi desiderati. Ad esempio, muovendosi dal Belpaese, è possibile esplorare posti meravigliosi come le coste maltesi, le scenografiche cittadine francesi fino alle coste iberiche, con una vacanza da sogno. Le navi da crociera offrono ospitalità, benessere, intrattenimento, emozioni ed esperienze sensoriali.

Specific description of the cruise services offered by Regent vs. MSC in abstract format Ne è un esempio il servizio di navi da crociera della compagnia Regent/MSC, che concede il privilegio di svegliarsi ammirando la bellezza di un panorama emozionante e di beneficiare di ogni confort. Per tutto il tempo della vacanza, inoltre, è possibile mantenersi in forma e godere di tanto divertimento acquatico.

\section{[Picture of a Regent vs. MSC cruise boat]}

Specific description of cruise services offered by Regent vs. MSC in abstract format

Regent/MSC crociere, durante la vacanza, offre anche sensazioni di rinnovata bellezza e relax, che aiutano a sentirsi più giovani, oltre che accompagnare in un mondo in continuo e affascinante movimento, un mondo fatto di stile e immaginazione.

Final sentence on sea-travels common to all experimental conditions

L'attrattività del Mediterraneo è indiscutibile, un mare che mette in comunicazione Paesi diversi per cultura e tradizioni, ma solo apparentemente lontani.

\section{References}

Aaker D.A. (1991). Managing Brand Equity: Capitalizing on the Value of a Brand Name. New York: The Free Press.

Appnexus (2018). The Digital Advertising Stats You Need for 2018. -- Available at https://www.appnexus.com/insights/whitepapers/2018-stats.

Aribarg A. and Schwartz E.M. (2017). Consumer Responses to Native Advertising. SSRN Electronic Journal. DOI: 10.2139/ssrn.2995467.

Bansal H.S. and Voyer P. A. (2000). Word-of-mouth processes within a services purchase decision context. Journal of Service Research, 3(2): 166-177. DOI: 10.1177/109467050032005.

Boerman S.C., van Reijmersdal E.A. and Neijens P.C. (2012). Sponsorship Disclosure: Effects of Duration on Persuasion Knowledge and Brand Responses. Journal of Communication, 62: 1047-1064. DOI: 10.1111/j.1460-2466.2012. 01677.x.

Brown G. (2011). Paid vs. Earned Media. MobileYouth. -- Available at https://www.slideshare.net/mobileyouth/graham-brown-mobileyouth-trendspaid-vs-earned-media).

Burgoon E.M., Henderson M.D. and Markman A.B. (2014). There are many ways to see the forest for the trees: A tour guide for abstraction. Perspectives on Psychological Science, 8(5): 501-520. DOI: 10.1177/1745691613497964.

Capestro M.G.P., Amatulli C. and Pichierri M. (2018). How abstract claims affect consumer's attitude towards advertising: Analysing the role of consumer's mental simulation and identification, SIM Conference Proceedings, 1-6. 
Cho C.-H. and Cheon H.J. (2004). Why do people avoid advertising on the internet?. Journal of Advertising, 33(4): 89-97. DOI: 10.1177/1745691613497964.

Davis J.J. (1994). Good ethics is good for business: Ethical attributions environmental and response to environmental advertising. Journal of Business Ethics, 13(11): 873-886. DOI: $10.1007 / \mathrm{bf00871701.}$

De Angelis M., Tassiello V., Amatulli C. and Costabile M. (2017). How language abstractness affects service referral persuasiveness. Journal of Business Research, 72: 119-126. DOI: 10.1016/j.jbusres.2016.10.006.

Dessart L., Veloutsou C. and Morgan-Thomas A. (2016). Capturing consumer engagement: duality, dimensionality and measurement. Journal of Marketing Management, 32(5-6): 399-426. DOI:10.1080/0267257x.2015.1130738.

Drèze X. and Hussherr F.X. (2003). Internet advertising: Is anybody watching?. Journal of Interactive Marketing, 17(4): 8-23. DOI: 10.1002/dir.10063.

Dube-Rioux L., Regan D.T. and Schmitt B.H. (1990). The cognitive representation of services varying in concreteness and specificity. Advances in Consumer Research, 17: 861-865.

Gregan-Paxton J. and John D.R. (1997). Consumer learning by analogy: A model of internal knowledge transfer. Journal of Consumer Research, 24(3): 266-284. DOI: $10.1086 / 209509$.

Gregan Paxton J., Hibbard J.D., Brunel F.F. and Azar P. (2002). "So that's what that is": Examining the impact of analogy on consumers' knowledge development for really new products. Psychology \& Marketing, 19(6): 533-550. DOI: $10.1002 /$ mar. 10023 .

Gutman J. (1982), A Means-End Chain Model Based on Consumer Categorization Processes. Journal of Marketing, 46(2): 60-72. DOI: 10.2307/3203341.

Harms B., Bijmolt T.H.A. and Hoekstra J.C. (2017). Digital Native Advertising: Practitioner Perspectives and a Research Agenda. Journal of Interactive Advertising, 17(2): 80-91. DOI:10.1080/15252019.2017.1357513.

Hinds P.J., Patterson M. and Pfeffer J. (2001). Bothered by abstraction: The effect of expertise on knowledge transfer and subsequent novice performance. Journal of Applied Psychology, 86: 1232-1243. DOI: 10.1037/0021-9010.86.6.1232.

Holmes V.M. and Langford J. (1976). Comprehension and recall of abstract and concrete sentences. Journal of Verbal Learning and Verbal Behavior, 15(5): 559-566. DOI: 10.1016/0022-5371(76)90050-5.

Howe P. and Teufel B. (2014). Native Advertising and Digital Natives: The Effects of Age and Advertisement Format on News. International Symposium On online Journalism, 4(1): 79-90.

IAB (2016), Ad Blocking: Who Blocks Ads, Why and How to Win Them Back. -Available at https://www.iab.com/insights/?topic=ad-blocking.

IAB (2019). The native Advertising playbook. -- Available at https://www.iab.com/insights/iab-native-advertising-playbook-2-0/.

Kim J. (2017). Native Advertising: Current Status and Research Agenda, Journal of Interactive Advertising, 17(2), 79-79, DOI: 10.1080/15252019.2017.1399704

Krouwer S., Poels K. and Paulussen S. (2017). To Disguise or to Disclose? The Influence of Disclosure Recognition and Brand Presence on Readers' Responses Toward Native Advertisements in Online News Media. Journal of Interactive Advertising, 17(2): 124-137. DOI: 10.1080/15252019.2017.1381579. 
Lachner A. and Nückles M. (2015). Bothered by Abstractness or Engaged by Cohesion? Experts' Explanations Enhance Novices' Deep-Learning. Journal of Experimental Psychology: Applied, 21(1): 101-115. DOI: 10.1037/xap0000038.

Marks D.F. (1973). Visual imagery differences in the recall of pictures. British Journal of Psychology, 64(1): 17-24. DOI: 10.1111/j.2044-8295.1973.tb01322.x.

Moeser S.D. (1974). Memory for meaning and wording in concrete and abstract sentences. Journal of Verbal Learning and Verbal Behavior, 13(6): 682-697. DOI: 10.1016/s0022-5371(74)80055-1.

Olson J. and Reynolds T. (1983). Understanding Consumers' Cognitive Structures: Implications for Advertising Strategy. In Percy L. and Woodside A. (Eds.). Advertising and Consumer Psychology. Lexington, MA: Lexington Books.

Pasqualotti L. and Baccino T. (2014). Online advertisement: how are visual strategies affected by the distance and the animation of banners?. Frontiers in Psychology, 5: 1-11. DOI: 10.3389/fpsyg.2014.00211.

Sajjacholapunt P. and Ball L.J. (2014). The influence of banner advertisements on attention and memory: human faces with averted gaze can enhance advertising effectiveness. Frontiers in Psychology, 5: 1-16. DOI: 10.3389/fpsyg. 2014.00166.

Schellekens G.A., Verlegh P.W. and Smidts A. (2010). Language abstraction in word of mouth. Journal of Consumer Research, 37(2): 207-223. DOI: 10.1086/651240.

Solomon M.R., Bamossy G.J., Askegaard S.T. and Hogg M.K. (2016) Consumer behavior: A European Perspective. Harlow (UK): Pearson.

So K.K.F., King C., Sparks B.A. and Wang Y. (2016). The Role of Customer Engagement in Building Consumer Loyalty to Tourism Brands. Journal of Travel Research, 55(1): 64-78. DOI:10.1177/0047287514541008.

Sohn D. (2009). Disentangling the Effects of Social Network Density on Electronic Word-of-Mouth (eWOM) Intention. Journal of Computer-Mediated Communication, 14(2): 352-367. DOI:10.1111/j.1083-6101.2009.01444.x.

Vaccaro C. (2016). Native Advertising. La nuova pubblicità. Milano: Hoepli.

Wojdynski B.W. (2016). The Deceptiveness of Sponsored News Articles. American Behavioral Scientist, 60(12): 1475-1491. doi:10.1177/0002764216660140.

Wojdynski B.W. and Evans N.J. (2016). Going Native: Effects of Disclosure Position and Language on the Recognition and Evaluation of Online Native Advertising. Journal of Advertising, 45(2): 157-168. DOI:10.1080/00913367. 2015.1115380.

Wojdynski B.W., Bang H., Keib K., Jefferson B.N., Choi D. and Malson J.L. (2017). Building a Better Native Advertising Disclosure. Journal of Interactive Advertising, 17(2): 150-161. DOI:10.1080/15252019.2017.1370401.

Yang S., Li D., Tao Z. and Li X. (2018). Search engine advertising for organic food: The effectiveness of information concreteness on advertising performance. Journal of Consumer Behaviour, 17(1): 47-56. DOI:10.1002/cb.1685. 